\title{
A REVOLUÇÃO DOS TURISTAS ${ }^{1}$
}

\author{
Francisco Viana ${ }^{2}$
}

\begin{abstract}
RESUMO: Oturismo cria a economia de mercado em Cuba e dispara um processo de modernização que a industrialização "ambicionada" pela Revolução não conseguiu fazer. Os negócios, que vivem um verdadeiro "boom" vêm se desenvolvendo com capitais europeus e latino-americanos, mas tendem a alcançar uma dinãmica maior, no Caribe, no caso de uma reaproximação de Cuba com os Estados Unidos.
\end{abstract}

PALAVRAS-CHAVE: Cuba; desenvolvimento turístico; economia de mercado; empresas turísticas; processo de modernização.

ABSTRACT: The tourism creates a market economy in Cuba and initiates a modernization process that the Revolution was not capable of doing. Business, presently in a "boom" situation, is developing with fore igncapital from Europe and Latin America, but will be in a very previleged situation in The Caribbean if The United States of America begins to help.

KEYWORDS: Cuba: touristic development; market economy; touristic industry; process of modernization.

\section{INTRODUÇÃO}

Duas Cubas, que se comportam como se fossem mundos paralelos, mas estão intimamente interligadas entre si, estão ganhando traços firmes e vivem em choque permanente. Uma é a Cuba de Revolução comunista, fechada para o mundo, onde ninguém sai do país sem ordem do governo, nem há o mínimo vestígio da moderna

1 Artigo que relata a visảo do autor sobre o turismo e a economia de mercado em Cuba durante viagem no início de 1993.

2 Jornalista formado pela Universidade Federal da Bahia. Mestre em Comunicação pela Universidade Federal do Rio de Janeiro. Editor da revista Isto é (1981 - 1993). End. para corresp.: Rua Pará, 90, apto. 131 - CEP 01243-020 - São Paulo SP - Brasil. 
economia de mercado. Essa é a Cuba que se contorce com as dores da queda do muro de Berlim, não se conforma com o naufrágio do império soviético e ainda respira o clima sufocante dos anos da guerra fria. Nela, o imperialismo norte-americano é tratado como o grande inimigo e a pátria cubana vista como "o primeiro território livre da América". A outra Cuba, a dos turistas, em número superior a $900 \mathrm{mil}$ por ano, não sabe o exato significado da palavra crise, vive de costas para o fracasso soviético e, a cada dia, vê os dólares norte-americanos ("verdadeiros", como são chamados) jorrar em abundância.

Há sete anos, os lucros do turismo não somavam US\$100 milhões. Hoje, já ultrapassaram a barreira de US $\$ 1$ bilhão, US $\$ 1.1$ bilhão projetado para 1993, passando à frente das receitas da cana-de-açúcar, e nada indica que vá parar de dar salto nas estatísticas.

Nesse novo pedaço de Cuba, que emerge da crise da Revolução, as palavras de ordem são, por paradoxal que possa parecer, todas de cunho eminentemente capitalista. É visível, em todas as iniciativas, a preocupação em ganhar dinheiro, a preocupação com a concorrência e, principalmente, com a abertura para o mundo. Aí, incluindo até os Estados Unidos, de preferência, embora esse, oficialmente, ainda seja um tema tabu.

Mas, a verdade é que na Cuba dos turistas a palavra contra-revolução simplesmente não existe e ninguém esquece que os EUA já foram o parceiro número um da ilha. Nos manuais dessa outra Cuba, geralmente impressos em sofisticadas gráficas da Espanha, não há referências ao marxismo. O que se lê são alusões às praias, ao sol, ao exotismo das mulheres, à alegria da música e ao clima de magia que envolve toda a Cuba, a partir de Havana.

Há uma conviç̧ão crescente que com o novo governo americano, o gelo dos últimos 35 anos irá se dissolver aos poucos, e, também aos poucos, Cuba voltará a ocupar a primeira posição nas rotas do Caribe.

\section{A ERA DO MERCADO E O TURISMO}

Está acontecendo exatamente o seguinte: o turismo está fazendo uma revolução. Cuba transita, sem escalas, de uma economia agráriaexportadora para uma economia de serviços. Sem os abalos sísmicos que caracterizaram a transição do Leste Europeu. Cuba, como a China, discretamente vem acoplando uma economia capitalista sobre uma base essencialmente socialista. E, essa aparente contradição, ao invés de entravar, estimula o processo.

Os avanços se dão sobre a formidável base educacional e da excelente rede hoteleira. O marxismo, como princípio organizador da sociedade, faz o resto. Isto porque permite que a infra-estrutura seja ampliada longe dos choques entre capital e trabalho que seria comum num país capitalista.

Em conseqüência, se desenvolve uma espécie de capitalismo de Estado de novo tipo. A balança só pende do lado da receita, porque não há fluxo turístico para fora do país. E, os lucros não são repassados para os trabalhadores em forma de salários, hoje muito mais comprimidos do que há uma década.

Novamente, o mercado se encarrega de atenuar as distorções. Como não se dá um passo em Cuba sem antes distribuir uma propina (gorjeta), o turismo acabou criando uma classe especial de trabalhadores.

Ofícialmente, estão no nível de qualquer cubano. Na prática, ganham e vivem melhor que grande parte da alta burocracia estatal.

\section{O SONHO DA INDUSTRIALIZAÇÃO}

O govemo faz um jogo de luz e sombra. Na teoria, pune com prisão qualquer cubano que seja preso com dólares no bolso. $\mathrm{Na}$ prática, permite que os dólares fluam normalmente, sem criar barreiras, e tampouco alimentar, por tênue que seja, um clima de terror.

Há explicações de ordem prática. É com a receita do turismo que a Cuba revolucionária está conseguindo dar alguma ordem ao caos em que mergulhou, há quatro anos, se o marco histórico for a queda do muro de Berlim. Na realidade, a crise se prolonga há mais de uma década, exatamente quando o país descobriu que a revolução industrial Idealizada no alvorecer da ascensão de Fidel Castro era um sonho tão distante quanto à revolução comunista na América Latina.

A crônica dessa época é a crônica das ironias, que marcam a história da Revolução. Na virada dos anos 70, Cuba apesar do esforço industrializante e de diversificação da agricultura, não passava de um imenso canavial. 
Como vitrine mais reluzente dos novos tempos, a ilha viu brotar, por força da ajuda soviética, as primeiras sementes daquilo que, nas projeções dos planos qüinqüenais, prometia ser um renovador ciclo de industrialização. Entre os projetos de grande porte se destacavam uma planta concentradora de níquel na cidade de Nícaro, uma siderúrgica em Havana e uma usina nuclear para produção de energia, esta em Cienfuegos.

Ao mesmo tempo, floresciam as indústrias de biotecnologia e de equipamentos médicos. Também, pareciam ganhar extraordinário dinamismo as indústrias de fertilizantes, inseticidas, alimentação, farinhas e bebidas.

No campo da agricultura, a colheita se desenhava igualmente bem-sucedida. A produção de laranjas foi multiplicada por quase sete vezes. A colheita de arroz saltou de 42 quilos de arroz por habitante para 54 quilos. $O$ pais ganhou auto-suficiência na produção de batata, tomate e banana. Mas um exame aprofundado da realidade demonstrava, com facilidade, que a balança da economia continuava a oscilar, perigosamente, no ritmo das colheitas de cana-de-açúcar, que nos melhores anos chegava a sete milhões de toneladas.

\section{OS CHOQUES DA CRISE E O TURISMO NA ECONOMIA}

Existiam, como aliás continuam a existir, fortes razōes para a modernização da economia estar mais voltada para o plano da ambição política do que para a realidade concreta. Já nos anos 70 , quatro crises sucessivas ganhavam forma nos bastidores e foram se adensando até virem à tona com a queda do muro de Berlim.

O mercado cubano, com dez milhōes de consumidores sempre foi uma muralha intransponivel para a industrialização em larga escala. Não bastasse as dimensōes quase liliputianas do mercado, a maior parte do petróleo consumido é importado e o país nunca contol com rios de forte capacidade para geração de energia elétrica. A esse leque de inconvenientes se soma o tenaz bloqueio económico notteamericano que fechou o mercado dos EUA para os produtos cubanos, de um lado, e criou toda a série de obstáculos para o comércio latino-americano com Cuba, de outro.
A revolução, ao reeditar métodos asfixiantes de controle que lembravam as práticas da Coroa espanhola, mergulhou a indústria de fumo, cujo dinamismo servia de contraponto à indústria do açúcar, numa crise que só encontrava paralelo no século XVIII.

O pais, embalado no sonho revolucionário, se fechou em si próprio. Até a Revolução, o turismo estava no epicentro da economia cubana. Havana, com o fulgurante Habana Hilton, rebatizado como Habana Libre, figurava para os turistas norte-americanos, guardada as proporções no tempo e na história, como Miami está hoje para os turistas brasileiros.

A ordem revolucionária não deixou pedra sobre pedra da antiga estrutura. Os empresários fugiram para Miami, a mão-de-obra qualificada também. Os cassinos foram destruídos. Os serviços de táxi estatizados. $\mathrm{E}$ as empresas turísticas banidas de cena. Os hotéis que não fecharam as portas, acabaram sendo transformados em alojamentos para revolucionários, técnicos da Europa Oriental ou, como o Habana Libre, adaptados para funcionar como centros de comando político.

Rapidamente, o turismo deixou de ter qualquer significado na balança comercial. Em parte, porque passou a se limitar exclusivamente a grupos controlados, muito limitados, sem qualquer condição de substituir o efervescente mercado americano. Em parte, porque, por medida de segurança, o governo resolveu virar as costas para essa fonte de renda, que no passado tinha sido um pilar central da economia.

A verdade, seja ela qual for, é que Cuba deixou de ser a Montecarlo do Caribe. E dos insignes personagens que antes costumavam freqüentá-la, a exemplo de Errol Flynn e Frank Sinatra, apenas o escritor Ernest Hemingway continuou a merecer honrarias da parte do novo regime.

\section{O TURISMO NA PONTA DA MODERNIZAÇÃO}

O resultado é que o marxismo punha e a realidade dispunha. Nada saiu como estava planejado.

$\mathrm{O}$ renascimento da indústria do turismo se daria, inicialmente, com as mudanças provocadas pela crise do petróleo. Pela primeira vez, ${ }^{0}$ governo se deu conta de que era absolutamente impraticável conti- 
nuar apostando na ficção da industrialização e na cana-de-açúcar como motores dinâmicos da economia.

A cana era o relato pronto e acabado da crise que começava a eclodir: os preços do mercado internacional, em queda livre, tornavam-se, a cada dia mais amargos, enquanto os custos internos de produção desafiavam a gravidade. A mecanização não avançou como se previa, o açúcar refinado, no país, não alcançava mais que $13 \%$ das safras, e havia o obstáculo da forte reação ao férreo controle estatal da produção.

A segunda onda viria com a queda do muro de Berlim e a imediata dissolução do império soviético. O desafio para preencher o vazio deixado pelo colapso da ex-URSS é formidável. Os soviéticos respondiam por $70 \%$ do comércio cubano.

Em seu conjunto, os países socialistas consumiam $85 \%$ de tudo aquilo que Cuba exportava. Entre 1989 e 1992, o comércio, com oque restou do extinto bloco soviético, caiu a quase a metade. E o que é pior, o suprimento de petróleo sofreu um golpe brutal. De 13 milhões de toneladas caiu para 6 milhões de toneladas, com tendência a encolher ainda mais. A chamada "opção zero", para definir esse período particular da Revolução, retrata com nitidez o drama. Foi entre um momento e outro que Cuba começou a se readaptar para reconquistar as posições perdidas no turismo. Dos grupos controlados se evoluiu para o turismo misto, isto é em grupos ou individual, mas sem qualquer controle de caráter político, a exceção da prévia aprovação do nome dos visitantes pelo governo.

Uma vez no país, o visitante pode se deslocar livremente, alojando-se em hotéis ou casa de amigos, sem qualquer restrição. A única exigência é que seja declarada, com precisão, o tempo de permanência e o local de hospedagem.

Hoje, o ciclo de mudanças começa a se completar. Há uma invasão de capitais italianos, espanhóis, alemães, suiços, mexicanos e jamaicanos nos negócios ligados ao turismo.

\section{O JOGO DA CONCORRÊNCIA ENTRE AS EMPRESAS DE TURISMO}

Teoricamente, a política liberativa é comandada pela Junta Central de Planificação, organismo que comanda os negócios da econo- mia. Na prática, o jogo da mudança é ditado pelo irresistivel magnetismo do mercado emergente.

Com notável êxito, há quatro companhias, todas de economia mista, disputando espaço. A primeira, dona da maior fatia do mercado, é a Cubanacan. As outras três são a Cubatur, a Gaivota e a Habanatur. Cubanacan, literalmente centro da ilha, foi o nome dado pelos índios ao primeiro assentamento criado por Colombo em Cuba. Nesse exato momento é o símbolo do espírito empreendedor do turismo cubano. Éo motor da penetraçãonos mercados da Europa e da América Latina, através de uma rede de escritórios instalados na Holanda, Espanha, Itália, Canadá e Brasil.

O segredo do êxito da Cubanacan, criada em 1987 para se opor à burocrática estrutura oficial, é a flexibilidade para operar no sistema de "joint ventures" ${ }^{3}$. Sob sua administração figuram 37 dos mais importantes hotéis da ilha, entre eles o Hotel Comododro e o Residencial Turístico Marina Hemingway, em Havana, além do Hotel Meliá, em Varadero.

A empresa, que se autodefine como uma Corporaçãode Turismo e Comércio Internacional, administra "shoppings", frotas de táxis, aviões e ônibus. Tem trânsito livre para negociações internacionais, se declara a favor e pratica publicamente a concorrência, além de dedicar especial atenção à excelência do atendimento.

As outras empresas são menores, menos ágeis, mas não menos eficientes. A Cubatur e Habanatur, que têm como tronco ancestral comum o antigo Instituto Nacional de Turismo, vêm se afirmando no turismo receptivo. A Gaviota, nascida de uma estrutura militar voltada para a segurança nacional, vem se especializando no turismo de aventura, esporte e excursões exóticas. Enquanto a Cubanacan procura resgatar o legado de Colombo, a Gaviota se volta para o legado do legendário Hemingway. O seu cenário principal de ação é a idílica enseada de Maria Gorda, a 48 quilômetros do povoado de Manuel Lazo, onde o escritor norte-americano costumava pescar secretamente. A idéia é transformar a região numa reserva para a caça submarina, captura de corais negros e a pesca.

3 "Joint ventures": associaçāo de empresas, nāo definitiva, para explorar capital e tecnologia. No caso cubano, Cuba entra com o mercado e as outras entram com o capital e o "know-how". 


\section{OS MITOS E O MARKETING TURÍSTICO}

A História, assim como a natureza, tornou-se uma fiel aliada do turismo em Cuba. Quem chega a Havana se surpreende como, de repente, personagens como Colombo, José Marti, Hemingway, Che Guevara e Camilo Cienfuegos se uniram, numa habilidosa campanha de propaganda, para esculpir a imagem de um país singular, onde não faltam sol, música, mulheres exóticas e revoluções.

O mercado de "bottons" com esses ilustres ícones, vendidos por US $\$ 1.50$ a US $\$ 8.00$, é tão comum quanto as filas que se sucedem à porta de La Bodequita del Medio, o bar onde Hemingway se nutria de rum, no Museu e na Praça da Revolução ou na Casa Partagás, onde são mostrados os segredos dos charutos cubanos.

De toda essa ilustre galeria, dois personagens nierecem relevo especial: Colombo e Hemingway. Colombo, há quinhentos anos, escreveu no seu diário de bordo a frase que se transformou numa das peças mais sólidas da propaganda turística de Cuba: "...y nunca cosa $\tan$ hermosa vido".

O Almirante, que desembarcou na ilha em 27 de outubro de 1492, procedente da ilha de San Salvador, nas Bahamas, com três caravelas, convencido de que havia chegado ao Continente asiático foi, afinal, reabilitado. A feição de cruel colonizador foi deixada de lado. Passou a merecer realce a sua visão de Cuba como "Llave del Nuevo Mundo" e "la joia de la corona".

Hemingway está onde sempre esteve: no papel de aventureiromor, símbolo da audácia e do gosto pelos prazeres da vida. A novidade é que ele, para efeitos de venda, passou a ser não um símbolo da cultura imperialista norte-americana, mas um produto tipicamente de Cuba, pais onde manteve uma imponente mansão, hoje transformada em museu, desde 1939 até sua morte em 1961.

\section{SALTO RENOVADOR ORIGINADO PELO TURISMO}

Nessa virada capitalista, o turismo em Cuba só fez inverter a antiga tendência à estagnação e à decadência. Os hotéis se reciclaram, com modemas instalações e serviços de qualidade. Entraram em moda os cursos de nível médio e universitário, que variam de um anก a três anos para formação de mão-de-obra. E hotéis do porte do Nacional,
Jabana Libre, Comodoro e Riviera passaram a funcionar como se ossem escola, nos moldes do SENAC, para aperfeiçoamento de zarçons, "maîtres" e gerentes às vésperas de receber o diploma.

As velhas frotas de táxi, com desconfortáveis automóveis de fabricação russa, estão sendo renovadas com Mercedez da década passada e confortáveis carros japoneses. O serviço de ônibus para transporte de grupos ganhou nova velocidade e hoje rivaliza com o que há de melhor em capitais européias, como Espanha e Portugal, em conforto, pontualidade e eficiência.

As novidades não terminam aí. As rotas se diversificaram. Hoje, não se limitam mais a Havana e a famosa praia de Varadero, cerca de 200 quilômetros da capital. O espaço explorado se estende por todo o arquipélago de Cuba, com seus $110.920 \mathrm{~km}^{2}$, circundado pela Isla de la Juventude um cinturão de arrecifes, na entrada do Golfo do México, entre o oceano Atlântico e o mar do Caribe. São, ao todo $3.500 \mathrm{~km}$ de costas, mais de 200 baias, portos e enseadas naturais, com águas quentes e cristalinas, muito sol e areias finas.

Por toda parte estão surgindo centros internacionais para excursionistas e clubes de caça e pesca. Os mais destacados: Villa Laguna Grande, Maria la Gorda, Camanguey, Trinidad, Holgain, Granma e Los Galeones. Fazem parte de uma estratégia voltada para explorar a mística aventura de Hemingway, que viveu na ilha, e nos dias atuais está sendo transformado num personagem vital do marketing internacional.

A Isla de la Juventud, vizinha da base norte-americana de Guantánamo, antes um santuário inacessível, passou a fazer parte dos roteiros turísticos. Já conta com 4 hotéis, 150 apartamentos e excursões organizadas para tirar partido dos atrativos locais, em particular uma cavema pré-histórica, chamada da Capela Sistina Cubana, onde foram descobertos restos humanos que datam de 1.100 anos.

\section{OS VÔOS DO "TURISMO SEXUAL"}

A grande novidade de Cuba não figura nos guias, nem nos planos ofíciais. É o "turismo sexual", uma alternativa pragmática para o estado de penúria em que vive a ilha.

A qualidade de vida, que já foi o orgulho da Revolução, caiu dramaticamente. A mortalidade infantil é baixa, 16 por mil, e a 
educação é, efetivamente, para todos. Mas faltam casas para morar, transporte, comida e em particular, acesso às "tiendas", abarrotadas de grifes do Primeiro Mundo, onde só os turistas podem comprar.

Nada mais comum nas ruas de Havana do que jovens (as "jineteras", no jargão local), entre 17 e 25 anos, se oferecendo para faze companhia a turistas em troca de um par de tênis, vestidos, convites para a Marina Hemingway ou algumas dezenas de dólares.

Não são prostitutas no sentido clássico do termo. São estudantes, professoras, operárias, ou simplesmente donas de casa que procuram um caminho prático para vencer a crise e, também, combater o tédio de uma cidade que fica de frente para a Flórida, mas de onde ninguém sai sem antes passar pelo crivo dos órgãos de segurança do Estado.

Um número cada dia maior de mulheres, em Cuba, podem ser vistas à tarde em Habana Vieja ou rodando no "hall" do Hotel Habana Libre. Podem ser vistas à noite nos cabarés ou nas ruas escuras de Havana e, também, podem ser chamadas ao quarto dos hóspedes pelos porteiros dos hotéis e motoristas de táxi, em troca de dois a dez dólares.

Em qualquer cabaré, a começar pelo Tropicana, que foi um símbolo da Havana dos idos de Batista, faz parte da rotina a oferta de programas com as artistas dos shows. $\mathrm{O}$ estilo é direto e insistente, mas discreto: as "chicas", como se diz em castelhano, são oferecidas ao cliente, em voz baixa nas mesas ou na entrada dos sanitários. Em caso de recusa, a oferta é repetida várias vezes, mas sempre como um convite, jamais como imposição. Embora não exista em Cuba uma cultura de mercado, esse tipo de atividade parece ganhar rapidamente uma estrutura e uma organização.

\section{A FORÇA DA TRANSIÇÃO}

Toda essa versatilidade é possível, porque Cuba vivencia uma original fase de distensão. $\mathrm{Na}$ Cuba revolucionária quem dá as cartas é Fidel Castro e seu irmão, o comandante Raul Castro, apontado oficialmente como seu sucessor e herdeiro político.

No dia-a-dia da Cuba que se movimenta para atenuar o obsoletismo das suas estruturas e os duros impactos da crise econômica, 0 contestável é um veterano revolucionário, Osamani Cienfuegos. Um registro necessário: Osamani é irmão de Camilo Cienfuegos, que dividia com Che Guevara as glórias de ter sido o braço direito de Fidel
Castro, em Sierra Maestra. Além do parente herói, Osamini, também um guerrilheiro revolucionário, sempre viveu cercado pela aura de ideólogo. Nunca foi partidário da estatização total da economia e sempre se bateu para que fossem lançadas pontes na direção da iniciativa privada dos países europeus, em particular.

Embora Cuba tenha conquistado resultados espetaculares, terá um longo caminho a percorrer. Principalmente, porque é impossível que continuem convivendo, e eternamente em choque, duas Cubas: a Cuba da Revolução e a Cuba dos Turistas.

Falta ao país, sobretudo, uma definição. Optará por uma abertura econômica, mas com o controle político nas mãos do Partido Comunista, como acontece na China? Tentará uma transição negociada, agora com a ascensão dos democratas nos EUA?

Uma vez respondida essas questões, Cuba tende rapidamente a ocupar posição central nas rotas para o Caribe. As bases para o futuro salto estão lançadas: a natureza é prodigiosa; a posição geográfica, a meia hora de avião dos Estados Unidos, é privilegiada; e há abundância de mão-de-obra qualificada.

Capitais, também é o que não falta. Como se não bastasse a corrida patrocinada por capitalistas europeus e jamaicanos, os cubanos exilados em Miami contam os dias para desembarcar na ilha.

Engana-se quem pensa que eles sonham apenas com a contrarevolução. Talvez, nesse momento de renovação da política dos Estados Unidos, a façanha mais ambicionada seja sincronizar Cuba com o mercado turístico americano e fazer, a partir de um novo epicentro em Miami, chover dólares sobre a ilha. A lógica é simples: Cuba, como dizia Colombo, é elo mágico do Caribe.

\section{BIBLIOGRAFIA}

BENEDICTO, José Luiz Luzón. 1988. Cuba. Madrid, Espanha: Ediciones Anaya. DONGHI, Tulio Halperin. 1969. História Contemporânea da América Latina. Madrid, Espanha: Alianza Editorial.

MARSHALL, Peter e LEWIS, Barry. 1990. Dentro de Cuba. Toledo, Espanha: Zena Publication. 